\title{
Research Paper: Recognition of Barriers in Physiotherapy Clinical Education From Students' Perspectives: A Content Analysis
}

\author{
Fatemeh Menatnia' $^{1}$, , Shohreh Noorizadeh Dehkordi ${ }^{*}$ (D), Mehdi Dadgoo' ${ }^{1}$ (C)
}

1. Department of Physiotherapy, School of Rehabilitation Sciences, Iran University of Medical Sciences, Tehran, Iran.

\begin{tabular}{|c|c|}
\hline $\begin{array}{l}\text { Use your device to scan } \\
\text { and read the article online }\end{array}$ & \\
\hline 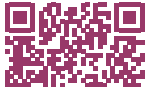 & $\begin{array}{l}\text { tion From Students' Perspectives: A Content Analysis. Iranian Rehabilitation Journal. 2019; 17(1):67-74. http://dx.doi. } \\
\text { org/10.32598/irj.17.1.67 }\end{array}$ \\
\hline 口ifing & dol http://dx.doi.org/10.32598/irj.17.1.67 \\
\hline
\end{tabular}

\section{(i) (3)}

Article info:

Received: 19 Sep 2018

Accepted: 13 Jan 2019

Available Online: 01 Mar 2019

\section{Keywords:}

Clinical clerkship, Physical therapy specialty, Qualitative research

\section{ABSTRACT}

Objectives: Clinical education in medical sciences is essential, because of its important role in the education of specialist skills. Physiotherapy specialization is among the main branches of medical sciences, which requires high academic and professional skills. One of the most important and effective methods to assess the quality of clinical education in physiotherapy is to review it from a student's perspective. Therefore, this study attempted to recognize the barriers of clinical education in physiotherapy students from their own perspective.

Methods: This qualitative study used content analysis method. Data were collected using semistructured interviews and the samples were selected by purposeful sampling method. We have considered maximum variation (gender, semester, educational level, place of residence) of persons in the sample selection. The data collection continued until saturation was reached. Participants included 13 physiotherapy undergraduate students who had completed at least 6 clinical education units.

Results: We extracted 182 original codes from interviews analysis. By eliminating and matching the data, we finally developed 4 categories, as follows: 1 . Personal and professional characteristics of clinical educators; 2 . Personal characteristics of students; 3 . Inadequate education system; 4 . The inappropriate clinical education environment.

Discussion: Clinical incompetency, inadequate clinical skills, and failure to observe professional ethics are the most frequent problems of clinical supervisors. Moreover, student's irresponsibility, inadequate participation, the lack of self-esteem in some students, and inappropriate planning and the implementation of clinical education of PT department and inappropriate interpersonal communication and facilities in clinical settings, can be considered as barriers for clinical education. Considering the obstacles and attempts to resolve them, reviewing the clinical education process can improve its quality. Reviewing the clinical education process seems to help recognize its barriers and attempt to resolving them. It seems to improve the quality of clinical education. 


\section{Highlights}

- Clinical education should be revised because of its importance in empowering graduates in the field of physical therapy.

- To understand the weaknesses of clinical clerkship programs, it is important to recognize the views of the students.

- Lack of student's motivation, non-ethical behaviors, ineffective communication, inefficient clinical training and lack of resources were the most important obstacles to empower students.

\section{Plain Language Summary}

It is very important to know the student's experiences as the main recipients of clinical education services. Results showed that clinical clerkship problems are classified into four broad areas: Problems with training instructors, with curriculum planning, with students, and with clinical education environment.

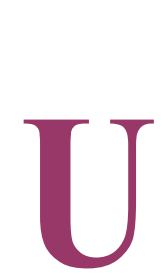

\section{Introduction}

niversities have an important role in educating specialist therapists, who are responsible to provide healthcare services for the community [1]. Clinical education is an integral part of educational programs, which combines both theoretical and practical education and plays an important role in developing and enhancing students' skills [2]. Bachelor's students of Physio Therapy (PT) have the opportunity to participate in various clinical fields and rehabilitate patients with the various conditions of orthopedics, neurology, cardiology, rheumatism, and so on. For being successful and effective, it is essential to monitor the current situation and recognize the strengths and modify weaknesses [3-5]. Therefore, it is essential for universities to provide continuous monitoring and evaluate clinical education to improve education quality.

Previous studies on the quality of clinical education in different courses, explored some problems such as clinical incompetency, inadequate clinical skills, and failure to observe professional ethics for clinical supervisors. Indeed, irresponsibility, inadequate participation, the lack of learning motivation and self-esteem in some students and inappropriate planning and the implementation of clinical education of PT department and inappropriate interpersonal communication and facilities in clinical settings are main problems in this regard [4-9].

Due to cultural and political changes over time, it is necessary to periodically assess the status of clinical education. Furthermore, the students are the main education recipients. Thus, it is necessary to use their experiences to identify the deficiencies and barriers. Therefore, the present study aimed to identify the barriers of clinical education in PT because of its importance and limited studies on this subject.

\section{Methods}

In this qualitative study, content analysis method (contractual type) was used. All clinical practice courses were presented during the last two years of undergraduate program; it was decided to conduct interviews with students in their last year of studies. Therefore, 13 undergraduate PT students who were in their last year of studies participated in the study. They were studying at the Rehabilitation Schools of Iran University of Medical Sciences, University of Tehran, Shahid Beheshti University, and University of Social Welfare and Rehabilitation Sciences. Students were enrolled into the study if they had passed at least 6 units out of the total 24 clinical units, during their studies.

They were selected for the interviews by purposeful sampling method, with a maximum variation in terms of the location of university, gender, semester, and residential place (far from family or with family). The interview process initiated after making the necessary arrangements. An appropriate place for conducting the interviews was arranged (a quiet place with good lighting), and consent forms were obtained from the study participants. Initially, two interviews were conducted as a trial run, to complete the questionnaire. Then, the interview initiated with a couple of open questions.

During the interview, the study participants' body language, facial expressions, non-verbal reactions, pauses, and statements that were emphasized by them, and voices were recorded. In the interviews, questions leading to 
"yes" and "no" answers were not used. In case of ambiguity, the researcher asked the interviewees to provide further explanations. Semi-structured interviews were used for data collection; thus, the entire conversation was recorded and transcribed. Afterwards, using data analysis, the important states were extracted and encrypted.

Conducting interviews and collecting data continued until a new code was added to the previous codes. Finally, data consisted of a sample of 13 PT students. To prevent interference with interviewee perspectives and paradigms, in addition to bracketing, peer checking and member checking were performed. Therefore, two co-authors and participants confirmed the validity of findings. To validate the data, the triangulation method was used in which one faculty member and one graduate student with 2 years of work experience, were both interviewed. The data analysis of these two interviews confirmed the codes received from previous interviews. Each interview lasted 25-53 minutes.

\section{Results}

We extracted 182 original codes from interviews analysis. By eliminating and matching the data, we finally developed 4 categories (Table 1).

Personal and professional characteristics of clinical educators

Table 2 presents the study participants' characteristics. This part includes three sub-categories, as follows: clini- cal incompetency, inadequate clinical skills, the lack of observing professional ethics. For example, one of the participants described the lack of responsibility in clinical supervisors: "Sometimes during working with the patient, we face a question, but there is no one to ask and we can't solve our problem without guidance" (A.A).

Another participant stated about the low level of supervisor's clinical skills: "Some clinical educators respond to student's questions or practice clinical skills based on their old knowledge. They don't update their information" (N.S). Observance of professional ethics is an important task for a clinical supervisor. One of the students discussed the lack of ethical considerations: "Sometimes, during working with a patient, the instructor enters the room and asks questions or shares comments in the presents of patient and humiliates us by this behavior" (F.K).

\section{Personal characteristics of students}

This part includes three sub-categories, as follows: student's irresponsibility, inadequate student participation in education, and the lack of self-esteem. One of the participants described the lack of student's responsibility: "Some students fail to follow the rules of clinical education, they have irregular entrance and exit time, and due to the lack of motivation or interest, they try not to involve in this process. They usually scape from work" (H.M).

Table 1. Categories and sub-categories derived from interviews with PT students

\begin{tabular}{cc}
\hline Category & Sub-Categories \\
\hline Personal and professional characteristics of clinical educators & Clinical incompetency \\
Inadequate clinical skills \\
Personal characteristics of students & lack of observing professional ethics \\
Inadequate education system & Student's irresponsibility \\
Inappropriate clinical education environment & Inadequate participation \\
& The lack of self-esteem \\
& Ine inappropriate planning \\
& Inappropriate interpersonal communication \\
\hline
\end{tabular}


Table 2. Describing the study participants

\begin{tabular}{|c|c|c|c|c|}
\hline No. & Age & Gender & Semester & University \\
\hline 1 & 24 & Female & 8 & Iran University \\
\hline 2 & 23 & Male & 7 & Iran University \\
\hline 3 & 23 & Female & 7 & Iran University \\
\hline 4 & 23 & Female & 8 & Tehran University \\
\hline 5 & 22 & Male & 7 & Tehran University \\
\hline 6 & 21 & Male & 6 & Tehran University \\
\hline 7 & 22 & Female & 7 & Tehran University \\
\hline 8 & 22 & Female & 7 & University of Social Welfare and Rehabilitation Sciences \\
\hline 9 & 21 & Female & 7 & University of Social Welfare and Rehabilitation Sciences \\
\hline 10 & 24 & Male & 8 & University of Social Welfare and Rehabilitation Sciences \\
\hline 11 & 22 & Male & 7 & Shahid Beheshti University \\
\hline 12 & 22 & Female & 6 & Shahid Beheshti University \\
\hline 13 & 22 & Male & 8 & Shahid Beheshti University \\
\hline
\end{tabular}

Iranian Rehabilitation Journa

The students also are not attentive. Their participation in the practice is inadequate. One of the participants stated: "Some students are not interested. This lack of motivation and interest negatively affects the time and quality of clinical education process" (S.F). To illustrate the lack of self-esteem, a participant explained: "Some students, despite adequate theoretical knowledge, have poor clinical performance, because they are not self-confident and they are afraid of making mistakes" (N.M).

\section{Inadequate education system}

Educational system problems include the following sub-categories: inappropriate planning and the poor management of clinical education programs. One of the participants described inappropriate planning: "Most of us must repetitively practice in various clinical centers that are not specialized" (A.M). To explain the poor management, another participant explained: "The education group of PT department disregards a proper assessment of the clinical education and supervisor's performance. In fact, clinical education in each center varies, depending on the interests of the supervisors and their own viewpoints" (M.M).

\section{The inappropriate clinical education environment}

This category includes two subsets; inappropriate interpersonal communication, and the lack of facilities in clinical settings. Lack of facilities and therapeutic equipment can affect the quality of clinical education. For example, a participant stated: "Some centers lack complete therapeutic equipment; e.g. there are not enough cabins in some centers, so the patients and students have to wait for a while" (A.A).

Most of the student's clinical experiences are environment-related. Inappropriate interactions of the center staff with students can turn clinical education into an unattractive environment. Another contributor talked about inappropriate interactions: "Sometimes during the work a nurse comes to our room, shows an aggressive behavior and forces students to stop their clinical work, to record a clinical report" (N.M).

\section{Discussion}

By categorizing, eliminating and matching the data, we finally developed 4 categories, as follows: 1. Personal and professional characteristics of clinical educators; 2 . Personal characteristics of students; 3 . Inadequate education system; and 4. The inappropriate clinical education 
environment. In the learning-education process, the students and educators are in close contact. Undoubtedly, their inadequate interaction negatively impact students' performance [10-12]. Studies have revealed that accompanying students with clinical supervisors has the greatest impact on the quality of clinical education [13-15].

The present study suggested that the characteristics of clinical supervisor such as irresponsibility, insufficient clinical skills and the lack of paying attention to professional ethics, are barriers to the effectiveness of clinical education. Chiang and Sloan in similar studies have argued that clinical proficiency, the ability to transfer skills to students, responsibility, effective communication with students, and adherence to the clinical ethics, are facilitators of clinical education $[10,16]$. To make the clinical education more effective, students also need to have features like willingness to learn, responsibility, high self-confidence, a sense of compassion and sympathy, sufficient information and a spirit of partnership with the supervisor $[1,4,5,11]$.

In this study, the participants' experiences suggested that laziness, the lack of motivation and self-esteem in students prevent the achievement of educational goals. Lack of interest in the field of study, considering the clinical education as an unimportant period, as well as the inappropriate training environment with respect to student's expectations are the main reasons for this issue. Other studies also reported that lack of self-confidence leads to depression and anxiety among students and affects their clinical performance $[17,18]$.

Taheri et al. in a descriptive study, argued that the individual characteristics of clinical supervisor and students, had the most significant effects on the clinical education of rehabilitation students [19]. From the perspective of contributors, the inappropriate planning and implementation of clinical education system programs are another hindrance to the process of clinical training. Abdi et al. also reported that the condition of clinical settings and undergraduate PT curriculum are undesirable $[3,4]$. In this study, the students acknowledged that despite the wide range of PT skills, they lacked a specific program for managing various cases in different clinical settings, such as orthopedics, neurology, and so on. According to them, clinical practice courses are tedious and repetitious.

It could be explained by the limited number of hospitals affiliated to the university, as well as the lack of specialized centers of clinical education. Moreover, the study participants complained about the lack of ad- equate opportunities to learn important clinical skills such as the interpretation of radiological images, manual techniques, dry needles, kinesiology tape, and so on. Kamali et al. also documented that undergraduate PT curriculum does not provide enough opportunities to learn clinical skills [5].

Perhaps the conversion of a bachelor's degree in PT to a professional doctorate can greatly compensate for the lack of required clinical skills. Another barrier to the efficiency of clinical education was the lack of adequate supervision over the performance of clinical educators and the implementation of training programs in clinical settings. Other studies have also reported that monitoring and evaluation is an important indicator in the measurement of achievement to educational goals, because it determines the strengths and weaknesses of training program $[1,3,5,20,21]$.

The most significant part of student's clinical experiences is formed in the context of the environment. Papathanasiou stated that the characteristics of learning environment are among the important and influential factors in clinical education [22]. The study participants acknowledged the lack of facilities and inappropriate interpersonal communication, as the most important environmental barriers. It seems that the unfair distribution of training spaces due to organizational policies and the lack of funds allocated for equipping the PT settings are among reasons for students' dissatisfaction with the training environment. Consistently, Dastgheibi, Kamali, Gard and Dunn, highlighted the role of environmental factors such as the availability of suitable space, appropriate facilities and equipment $[4,5,23,24]$.

It is suggested that the quality of clinical education be assessed through periodic evaluations, to improve the quality of clinical education by empowering the strengths and defeating barriers.

\section{Conclusion}

Clinical incompetency, inadequate clinical skills, and failure to observe professional ethics are the most frequent problems among clinical supervisors. Furthermore, student's irresponsibility, inadequate participation, the lack of self-esteem in some students, inappropriate planning, the implementation of clinical education of PT department, and inappropriate interpersonal communication and facilities in clinical settings, can be considered as barriers for clinical education. Considering the obstacles and attempts to resolve them, reviewing the clinical education process can improve the quality 
of clinical education. It seems to improve the quality of clinical education.

Participants of this research were selected from Medical Sciences universities in Tehran. Therefore, the results cannot be generalized to other rehabilitation schools in other cities.

\section{Ethical Considerations}

\section{Compliance with ethical guidelines}

The ethics code was received (IR.IUMS.REC 1395.9311340008).

\section{Funding}

This paper was extracted from the MSc. thesis of Fatemeh Menatnia in Department of Physiotherapy, School of Rehabilitation Sciences, Iran University of Medical Sciences, Tehran.

\section{Authors contributions}

All authors contributed in preparing this article.

\section{Conflict of interest}

The authors declare no conflict of interest.

\section{Acknowledgements}

We appreciate all the faculty members and supervisors of clinical education, physiotherapy students and hospital staff.

\section{References}

[1] Nodehi Moghadam A, Abdi K, Kashfi Ardehjan P. Exploring the challenges of physiotherapy clinical education: A qualitative study. Iranian Rehabilitation Journal. 2017; 15(3):207-14. [DOI:10.29252/nrip.irj.15.3.207]

[2] Davies C, Welham V, Glover A, Jones L, Murphy F. Teaching in practice. Nursing Standard. 1999; 13(35):33-8. [DOI:10.7748/ns1999.05.13.35.33.c2604] [PMID]

[3] A'bdi K, Maddah SSB, Rahgozar M, Dalvandi A. [Evaluation of educational situation of rehabilitation branches in welfare and rehabilitation university from the student's viewpoint in educational year 2003-2004 (Persian)]. Archives of Rehabilitation. 2007; 7(4):57-64.

[4] Dastgheibi SMR, Kamali M, Dadgoo M, Chabok A. [Internal elements and external factors affecting physiotherapy clinical education from physiotherapy student's perspectives: Qualitative study (Persian)]. Journal of Research in Rehabilitation Sciences. 2014; 10(3):393-407.

[5] Kamali M, Dastgheibi SMR, Chabok K, Dadgoo M, Ghanaatian S. [Physiotherapy students' experiences from clinical education processes: A qualitative study (Persian)]. Journal of Research in Rehabilitation Sciences. 2013; 9(5):818-32.

[6] Abdi K, Vameghi R, Seyyedi Iraj S, Safi MH. [Designing the valid indexes for assessment of situation of clinical education in rehabilitation courses (Persian)]. 2013; 5(9):23-34.

[7] Changiz T, Malekpour A, Zargham-Boroujeni A. Stressors in clinical nursing education in Iran: A systematic review. Iranian Journal of Nursing and Midwifery Research. 2012; 17(6):399-407. [PMID] [PMCID]

[8] Dean CM, Stark AM, Gates CA, Czerniec SA, Hobbs CL, Bullock LD, et al. A profile of physiotherapy clinical education. Australian Health Review. 2009; 33(1):38-46. [DOI:10.1071/ AH090038] [PMID]

[9] Kariminejad R, Vameghi R, Abdi K, Bakhshi E, Mohammdzadeh Z. [A comparison of the viewpoints of clinical educators and students of the university of social welfare and rehabilitation sciences toward clinical training status of rehabilitation disciplines in 2013-14 (Persian)]. Strides in Development of Medical Education. 2015; 12(3):485-95.

[10] Chiang HH. Students' perceptions of effective and ineffective clinical instructors. Journal of Nursing Education. 2005; 44(4):187-92. [PMID]

[11] Knox GM, Snodgrass SJ, Stanton TR, Kelly DH, Vicenzino B, Wand BM, et al. Physiotherapy students' perceptions and experiences of clinical prediction rules. Physiotherapy. 2017; 103(3):296-303. [DOI:10.1016/j.physio.2016.04.001] [PMID]

[12] McMahon S, Cusack T, O'Donoghue G. Barriers and facilitators to providing undergraduate physiotherapy clinical education in the primary care setting: A three-round Delphi study. Physiotherapy. 2014; 100(1):14-9. [DOI:10.1016/j.physio.2013.04.006] [PMID]

[13] Démeh W, Rosengren K. The visualisation of clinical leadership in the content of nursing education- A qualitative study of nursing students' experiences. Nurse Education Today Journal. 2015; 35(7):888-93. [DOI:10.1016/j.nedt.2015.02.020] [PMID]

[14] Goldie J, Dowie A, Goldie A, Cotton P, Morrison J. What makes a good clinical student and teacher? An exploratory study. BMC Medical Education. 2015; 15:40. [DOI:10.1186/ s12909-015-0314-5] [PMID] [PMCID]

[15] St-Onge C, Chamberland M, Lévesque A, Varpio L. The role of the assessor: Exploring the clinical supervisor's skill set. The Clinical Teacher. 2014; 11(3):209-13. [DOI:10.1111/ tct.12126] [PMID]

[16] Sloan G. Good characteristics of a clinical supervisor: A community mental health nurse perspective. Journal of Advanced Nursing. 1999; 30(3):713-22. [DOI:10.1046/j.13652648.1999.01121.x] [PMID]

[17] Delany C, Bragge P. A study of physiotherapy students' and clinical educators' perceptions of learning and teaching. Medical Teacher. 2009; 31(9):e402-e11. [DOI:10.1080/01421590902832970] [PMID] 
[18] Melo K, Williams B, Ross C. The impact of nursing curricula on clinical practice anxiety. Nurse Education Today. 2010; 30(8):773-8. [DOI:10.1016/j.nedt.2010.02.006] [PMID]

[19] Taheri AR, Forghany S, Atapour S, Hassanzadeh A. [The effective clinical teaching from faculty members'and rehabilitation students' point of view (Persian)]. Iranian Journal of Medical Education. 2012; 11(9):1131-9.

[20] Safavi-Farokhi Z, Bakhtiary AH, Fatemi E, Hagihasani A, Amouzadeh-Khalili M. [Internal evaluation of physiotherapy department of Semnan University of Medical Sciences (Persian)]. Koomesh. 2011; 12(4):349-55.

[21] Zamanzadeh V, Abdollahzadeh F, Lotfi M, Aghazadeh A. [Assessing clinical education fields from the viewpoints of nursing and midwifery instructors in Tabriz University of Medical Sciences, 2006 (Persian)]. Iranian Journal of Medical Education. 2008; 7(2):299-307.

[22] Papathanasiou IV, Tsaras K, Sarafis P. Views and perceptions of nursing students on their clinical learning environment: Teaching and learning. Nurse Education Today Journal. 2014; 34(1):57-60. [DOI:10.1016/j.nedt.2013.02.007] [PMID]

[23] Dunn SV, Hansford B. Undergraduate nursing students' perceptions of their clinical learning environment. Journal of Advanced Nursing. 1997; 25(6):1299-306. [DOI:10.1046/ j.1365-2648.1997.19970251299.x]

[24] Gard G, Dagis D. Physiotherapy students' perceptions of learning in clinical practice in Sweden and India. Nurse Education Today Journal. 2016; 36:381-6. [DOI:10.1016/j. nedt.2015.10.001] [PMID] 
This Page Intentionally Left Blank 